\section{Endarterectomía Carotídea}

\author{
Dr. Julio Yarmuch \\ Editor \\ Revista Chilena de Cirugía \\ Presente
}

\section{Estimado Dr. Yarmuch:}

Hemos leído con atención el interesante trabajo "Endarterectomía Carotídea con Medición de Presión de Muñón, Manejo Hemodinámico y Uso Selectivo de Shunt" publicado en nuestra Revista por el Dr. Juan Bombin y cols. ${ }^{1}$

Felicitamos a los autores por su detallada comunicación, la que nos ha estimulado a verificar nuestra propia experiencia respecto del uso de shunt.

En nuestra institución efectuamos la endarterectomía carotídea (EC) preferentemente bajo protección cerebral con shunt, lo que nos permite tomar todo el tiempo necesario para el entrenamiento de residentes en esta delicada técnica. A diferencia de los autores, nuestra preferencia es el shunt de Sundt, técnicamente más simple y amigable de usar (Integra NeuroSciences, NJ, USA). Sin embargo, excepcionalmente y por lo general debido a condiciones locales de la arteria carótida, nos vemos enfrentados a efectuar la intervención prescindiendo de dicha protección.

Entre diciembre de 1977 y abril de 2018, hemos efectuado 1.821 EC, de las cuales 93 las completamos sin uso de shunt. El 60,22\% de los pacientes era asintomático, y los 93 tenían permeabilidad del eje carotideo contralateral, confirmada en las imágenes preoperatorias. La indicación de no usar shunt fue: localización alta de la bifurcación carotídea, extensión de ateromatosis severa hacia la carótida común proximal o la imposibilidad técnica para instalación del shunt.

La morbilidad global a 30 días (neumonía, arritmia, etc.) en los 93 casos de EC sin shunt fue $2,15 \%$, un caso presentó una complicación neurológica (hemorragia intracerebral $=1,08 \%$ ), con mortalidad a 30 días de $0 \%$.
Para comparación, en los 1.685 casos en que realizamos EC con shunt (excluidos los casos de EC combinada con cirugía cardíaca), el 47,3\% era asintomático y la morbilidad global a 30 días fue $6,23 \%$. La tasa de eventos neurológicos (transitorios y permanentes) a 30 días alcanzó $0,77 \%$, y la mortalidad 30 días fue $0,42 \%$.

La diferencia en la tasa de pacientes sintomáticos/asintomáticos entre ambos grupos alcanzó significación estadística $(p=0,02)$. Sin embargo, no hubo diferencia significativa en las cifras de mortalidad a 30 días ( $\mathrm{p}=0,38$, RR 1,29 IC95\% 0,07 a 22,63) ni en la morbilidad neurológica a 30 días $(p=0,69, R R$ 1,39 IC 95\% 0,18 a 10,54) lo que confirma lo establecido por el Dr. Bombin y cols en su discusión, siendo lo más importante la adecuada selección de pacientes, su monitorización intra y posoperatoria, una técnica depurada, (la que el cirujano domine y ejecute con frecuencia).

Al final, como señala Hertzer²: en cirugía carotídea, lo importante son los resultados para el paciente.

\section{Bibliografía}

1. Bombin J, Kotlik A, Córdova G, Gómez C, Bombin M. Rev Chil Cir. 2018;70:35-9.

2. Hertzer HR. J Vasc Surg. 1995;21:6-15.

Atentamente

Cristian Zárate B., Obren Drazic B., Leopoldo Mariné M. y Francisco Valdés $E$. Departamento de Cirugía Vascular y Endovascular. Facultad de Medicina, Pontificia Universidad Católica de Chile.

Correspondencia: Dr. Francisco Valdés E. pancho.valdes.e@gmail.com 